\title{
A ASSOCIAÇÃO DE PROTEÇÃO E ASSISTÊNCIA AOS CONDENADOS (APAC): RESSOCIALIZAÇÃO E DIGNIDADE DA PESSOA HUMANA ${ }^{1}$
}

THE ASSOCIATION OF PROTECTION AND ASSISTANCE TO CONDEMNED (APAC): RESOCIALIZATION AND DIGNITY OF THE HUMAN PERSON

Karina GONZAGA ${ }^{2}$

Cildo GIOLO JÚNIOR ${ }^{3}$

ISSUE DOI: $10.21207 / 2675-0104.2019 .898$

\section{RESUMO}

O objetivo da presente pesquisa é analisar a estrutura e funcionamento das APACs contextualizandoas em contraste às instituições prisionais tradicionais, tendo em vista o princípio constitucional da dignidade da pessoa humana e a Lei de Execução Penal, instituída pela Lei $\mathrm{N}^{\mathrm{o}} 7210 / 84$. Diante da constante problemática do sistema padrão que enfrenta problemas como superlotação, alta taxa de

${ }^{1} \mathrm{O}$ presente artigo sintetiza a monografia de conclusão da pesquisa realizada para o Programa Interno de Bolsas de Iniciação Cientítica (PIBIC 2018-2019) da Faculdade de Direito de Franca (FDF), Franca/SP.

${ }^{2}$ Discente da Faculdade de Direito de Franca (FDF), Franca/SP. Bolsista do Programa Interno de Bolsas de Iniciação Cientítica (PIBIC 2018-2019). Currículo Lattes: http://lattes.cnpq.br/2554034924794288. Contato: karinagonzaga@ @hotmail.com.

${ }^{3}$ Pós-Doutor em Direitos Humanos pelo "Ius Gentium Conimbrigae" (IGC/CDH) da Faculdade de Direito da Universidade de Coimbra (UC), Portugal. Doutor em Direito pela Universidade Metropolitana de Santos (UNIMES). Doutor em Ciências Jurídicas e Sociais pela UMSA (Buenos Aires - Argentina). Mestre em Direito Público pela Universidade de Franca (UNIFRAN), Franca/SP. Especialista em Direito Processual Civil na Faculdade de Direito de Franca (FDF), Franca/SP. Graduado em Direito pela Faculdade de Direito de Franca (FDF), Franca/SP. Professor Titular da cadeira de Direito Civil na Faculdade de Direito de Franca (FDF), Franca/SP. Currículo Lattes: http://lattes.cnpq.br/9079687915501476. Contato: drcildo@gmail.com. 
reincidência e controle pelas facções criminosas, as APACs emergem como modelo alternativo focado na humanização da execução penal, proporcionando condições para a recuperação e proteção da sociedade, possibilitando uma reflexão sobre o sistema penitenciário como um todo.

Palavras-chave: apac; dignidade; ressocialização.

\begin{abstract}
The aim of this research, within the scope of Criminal Law, is to analyze the structure and functioning of APACs (Association of Protection and Assistance of the Condemned), contextualizing them in contrast to traditional prison institutions, in view of the dignity of the human person and the Criminal Enforcement Law, instituted by Law $n^{\circ}$. 7210/84. In the face of the constant problem of the standard system that confronts problems such as overcrowding, high recidivism and control by criminal gangs, APACs arise as an alternative model focused on the humanization of criminal execution, providing conditions for recovery and protection of society, enabling a reflection on the penitentiary system as a whole.
\end{abstract}

Keywords: apac; dignity; resocialization

\title{
INTRODUÇÃO
}

A presente pesquisa ancorada no Direito Penal visa analisar o funcionamento das APACs (Associação de Proteção e Assistência aos Condenados) em contraste às instituições prisionais tradicionais à luz do princípio constitucional da dignidade da pessoa humana e da Lei de Execução Penal, instituída pela Lei no 7.210 de 11 julho de 1984. Neste contexto caótico do aprisionamento em massa (como superlotação de presídios), com baixas condições estruturais para atender ao objetivo de ressocialização e, consequentemente com altos índices de reincidência criminal, as APACs surgem como modelo alternativo com o foco na humanização do cumprimento das penas privativas de liberdade, proporcionando condições para a recuperação, proteção da sociedade. É por se tratar de um modelo diferente e funcional, em divergência ao sistema prisional padrão, que o estudo do Método APAC toma relevância e justificativa social. A pesquisa se utiliza de fontes de análise tradicionais como Beccaria, Foucault, Goffman, Baratta e as publicações dos tribunais que apostaram no modelo como política pública.

\section{RESSOCIALIZAÇÃO NA LEI 7.210/84}

A Lei de Execução Penal do país, sendo marco normativo na ordenação jurídica sobre o tema. Nesta é descrita de maneira bastante vasta 
tanto a finalidade da execução penal como os princípios que devem nortear sua aplicação. O surgimento da Lei de Execução Penal (LEP) tem relação intrínseca com a acentuada dificuldade do país em cuidar dos condenados e internados, bem como reconhecer que tais pessoas são detentoras de dignidade humana e demais direitos como qualquer outro ser em liberdade. Foi necessário o surgimento de uma lei que declarasse e resguardasse os direitos e condições mínimas das pessoas em situação carcerária.

A lei dispõe desde: da Classificação - dos internos, de forma a garantir à individualização da pena -; da Assistência (ao condenado e ao egresso); do Trabalho; dos Deveres, dos Direitos e da Disciplina; dos Órgãos da Execução Penal; do Conselho Nacional de Política Criminal e Penitenciária; do Juízo da Execução; do Ministério Público; do Conselho Penitenciário; dos Departamentos Penitenciários; do Patronato; do Conselho da Comunidade; da Defensoria Pública; dos Estabelecimentos Penais; da Penitenciária; da Colônia Agrícola, Industrial ou Similar; da Casa do Albergado; do Centro de Observação; do Hospital de Custódia e Tratamento Psiquiátrico; da Cadeia Pública; da Execução das Penas em Espécie; das Penas Restritivas de Direito; da Suspensão Condicional; da Pena de Multa; da Execução das Medidas de Segurança; da Cessação da Periculosidade; das Conversões; do Excesso ou Desvio; da Anistia ou Indulto. ${ }^{4}$

A Carta Magna já assegura a integridade física e moral de todos, condenados ou não, assim, no mesmo sentido, a LEP apenas reitera de maneira mais específica quais devem ser as condições prestadas para que o cumprimento da pena se preste a suas finalidades sem ofensa à dignidade do ser humano em sua totalidade. A criação da Lei 7.210/1984 representa um avanço histórico na execução penal, pois evidencia claramente, desde seu primeiro artigo, os objetivos da execução penal quais sejam os de efetivar o disposto em sentença penal e ainda proporcionar para o preso ou internado condições harmônicas de integração para o cumprimento da mesma. $^{5}$

Podemos entender que na LEP estão instituídos três objetivos centrais. $\mathrm{O}$ primeiro deles diz respeito à preservação e garantia do bemestar do apenado, sendo o segundo a importância da classificação do encarcerado e da individualização da pena. $\mathrm{O}$ último objetivo seria o

\footnotetext{
4 BRASIL. Lei $\mathbf{n}^{\mathbf{0}} \mathbf{7 . 2 0 1 0}$ de $\mathbf{1 1}$ de julho de $\mathbf{1 9 8 4}$. Disponível em: http://www.planalto.gov.br/ccivil_03/leis/17210.htm. Acesso em: 01 de julho de 2019.

${ }^{5}$ SILVA, Jane Ribeiro (Org.). A execução penal à luz do método APAC. Belo Horizonte: Tribunal de Justiça de Minas Gerais, 2012. p. 34, 54 e 108.
} 
oferecimento da assistência e deveres necessários para o condenado ao longo do cumprimento de sua pena. ${ }^{6}$

Em seu primeiro artigo traz a contribuição de se entender a pena como um processo necessariamente ressocializador, avanço muito importante para a execução das penas no Brasil $^{7}$ :

Art. $1^{\circ}$ A execução penal tem por objetivo efetivar as disposições de sentença ou decisão criminal e proporcionar condições para a harmônica integração social do condenado e do internado. ${ }^{8}$

Esta harmônica integração do condenado diz respeito a condições materiais e assistenciais que o ambiente carcerário precisa conter para uma aplicação adequada da pena, bem como um condições para a reintegração social após o período de encarceramento.9

As garantias fundamentais dos condenados, como o bem-estar já mencionado, são previstas na lei e são parte do que se propõe para que a pena atinja seus objetivos não puramente punitivos. $\mathrm{O}$ artigo $3^{\circ}$ da LEP, por exemplo, traz que os condenados não podem ser privados de direitos que não sejam os impostos pela condenação, além de não poder haver qualquer tipo de discriminação (racial, social, religiosa, política, etc. ${ }^{1011}$

Não se pode perder de horizonte que a proteção do indivíduo apenado é um princípio constitucional, tratando, segundo o artigo $5^{\circ}$, XLIX, que "- é assegurado aos presos o respeito à integridade física e moral". ${ }^{12}$

Além disso é de vital importância entender que a lei tem como objetivo também a reinserção do condenado na sociedade, ressocializando$\mathrm{o}$, com respeito à sua dignidade, moral e direitos. ${ }^{13}$

\footnotetext{
${ }^{6}$ MARQUES JÚNIOR, Gessé. A lei de execuções penais e os limites da interpretação jurídica. Rev. Sociologia Política, Curitiba, v. 17, n. 33, p. 145-155, jun. 2009. p. 148.

${ }^{7}$ HENRIQUE, Derli Carolino da Silva. A Lei de Execução Penal e a Ressocialização do Apenado. Rede Doctum De Ensino, Vitória, dezembro de 2017. p. 17 e 18.

8 BRASIL. Lei $\mathbf{n}^{\mathbf{0}} \mathbf{7 . 2 0 1 0}$ de 11 de julho de 1984 . Disponível em: http://www.planalto.gov.br/ccivil_03/leis/17210.htm. Acesso em: 01 de julho de 2019.

${ }^{9}$ MARQUES JÚNIOR, Gessé. A lei de execuções penais e os limites da interpretação jurídica. Rev. Sociologia Política, Curitiba, v. 17, n. 33, p. 145-155, jun. 2009. p. 148.

${ }^{10}$ Ibidem, p. 148.

11 BRASIL. Lei $\mathbf{n}^{\mathbf{0}} \mathbf{7 . 2 0 1 0}$ de 11 de julho de 1984 . Disponível em:http://www.planalto.gov.br/ccivil_03/leis/17210.htm. Acesso em: 01 de julho de 2019.

${ }^{12}$ BRASIL, Constituição (1988). Constituição da República Federativa do Brasil. Sã o Paulo: Rideel, 2016.

${ }^{13}$ HENRIQUE, Derli Carolino da Silva. A Lei de Execução Penal e a Ressocialização do Apenado. Rede Doctum De Ensino, Vitória, dezembro de 2017. p. 16.
} 
Dessa forma, em teoria, a Lei de Execução Penal assegura a aplicabilidade da pena conforme os ditames constitucionais, garantindo, além da punibilidade, direitos inerentes ao homem em situação carcerária, sendo o maior e norteador dos demais direitos, a dignidade da pessoa humana. Prevê ainda a referida Lei, em seu artigo $84 \S 3^{\circ}$ e incisos, os propósitos de individualização da pena com vistas a realização de adequada separação de presos. ${ }^{14}$

A LEP prevê ainda, nos artigos 10 e 11 o papel do Estado em auxiliar o preso para alcançar ao final a ressocialização do mesmo, provendo assistência "I) material; II) à saúde; III) jurídica; IV) educacional; V) social; VI) religiosa." $" 1516$

Estas assistências ofertadas ao condenado e que são previstas pelos artigos 10 a 24 da LEP são essenciais para a garantia dos direitos básicos do mesmo, além de fundamentos para o alcance do objetivo ressocializador da pena. Além disso, os artigos 25 à 27 se voltam para a atenção ao condenado egresso da instituição prisional, prevendo apoio e orientação para o mesmo, e também auxílio na obtenção de um vaga de emprego. Elementos de extrema necessidade para a reinserção do egresso na sociedade e, consequentemente, para a redução da reincidência. ${ }^{17} 18$

A presente lei também se pauta na individualização da pena como um meio básico para o processo ressocializador, e, para tal fim, contribui com a previsão do direito do condenado de reduzir sua pena através do estudo e do trabalho. Estes, por sua vez, contribuem com o desenvolvimento pleno dos condenados, contribuindo com a ressocialização na medida em que se aprende um ofício durante o período de encarceramento que pode ser útil na vida egressa. Esta individualização da pena é, de forma geral, um meio de se garantir também o respeito à dignidade humana do apenado. ${ }^{19}$

\footnotetext{
${ }^{14}$ BUTELLI, K.A.D. Projeto Novos Rumos na Execução Penal e o Método APAC - Uma abordagem jurídica e filosófica acerca da Lei 7210/84. 2011. 34 f. Monografia (Graduação Em Direito) UniverCidade - Méier, Rio de Janeiro, 2011. p. 35.

${ }^{15}$ Ibidem, p. 35.

16 BRASIL. Lei $\mathbf{n}^{\mathbf{7}} \mathbf{7 . 2 0 1 0}$ de 11 de julho de $\mathbf{1 9 8 4}$. Disponível em: http://www.planalto.gov.br/ccivil_03/leis/17210.htm. Acesso em: 01 de julho de 2019.

${ }^{17}$ MARQUES JÚNIOR, Gessé. A lei de execuções penais e os limites da interpretação jurídica. Rev. Sociologia Política, Curitiba, v. 17, n. 33, p. 145-155, jun. 2009. p. 149.

18 BRASIL. Lei $\mathbf{n}^{\mathbf{0}} \mathbf{7 . 2 0 1 0}$ de 11 de julho de 1984. Disponível em: http://www.planalto.gov.br/ccivil_03/leis/17210.htm. Acesso em: 01 de julho de 2019.

${ }^{19}$ HENRIQUE, Derli Carolino da Silva. A Lei de Execução Penal e a Ressocialização do Apenado. Rede Doctum De Ensino, Vitória, dezembro de 2017. p. 15.
} 
Todos estes aspectos se coadunam para a observância do princípio da humanização da pena. Este envolve o entendimento que o apenado - assim como qualquer outro cidadão livre - é sujeito de direitos e deveres, com harmonia entre estes, ou seja, sem excesso de regalias ou de punições. $^{20}$

\section{DIGNIDADE DA PESSOA HUMANA E A CONSTITUIÇÃO FEDERAL DE 1988}

A dignidade da pessoa humana é, desde as últimas décadas, tema amplamente debatido no campo da ética A dignidade humana, inicialmente de base filosófica, é sobretudo um valor, relacionada a concepção de virtude, justiça e bondade. Por conseguinte, acompanha outros valores de grande importância para o âmbito jurídico, como justiça e segurança, podendo assim ser considerada como fundamentação moral dos direitos humanos e direitos fundamentais. Já quando relacionada à política, ela passa a constituir documentos legais de ordem nacional e internacional, tornando-se fundamento dos Estados democráticos, inicialmente a cargo dos Poderes Legislativo e Executivo, com a posterior incorporação pelo Poder Judiciário, elevando-se a um conceito jurídico, sendo oficialmente um dever normativo. Atualmente então, a dignidade humana assumiu a posição de princípio jurídico, de ordem constitucional, constante de forma explícita e implícita ao longo do sistema legal. ${ }^{21}$

Houve então uma aproximação dos valores éticos ao Direito, tornando este último repleto de valoração moral. Nos casos de maior conflito e dificuldade de solução, antes mesmo de sua positivação ou abarcada pela jurisprudência, já se recorria à dignidade humana como elemento extrajurídico para a construção de um entendimento justo. Portanto, sua oficialização nos documentos jurídicos consolidou o processo de atribuição de caráter normativo ao conceito de dignidade humana e consequentemente afastou a ideia de que o Poder Judiciário havia criado normas sem a devida legitimidade. ${ }^{22}$

\footnotetext{
${ }^{20}$ MARQUES JÚNIOR, Gessé. A lei de execuções penais e os limites da interpretação jurídica. Rev. Sociologia Política, Curitiba, v. 17, n. 33, p. 145-155, jun. 2009. p. 149

${ }^{21}$ BARRoso, Luís Roberto. A Dignidade da Pessoa Humana no Direito Constitucional Contemporâneo: Natureza Jurídica, Conteúdos Mínimos e Critérios de Aplicação. Versão provisória para debate público. Mimeografado, 2010. p. 10.

${ }^{22}$ Ibidem, p. 11.
} 
Para o entendimento do conceito, importante considerar que todo ser humano já é dotado de dignidade, pois este não é um conceito apartado do outro. É um valor intrínseco da natureza humana: se existe, é dotado de dignidade. A dignidade assim entendida como um valor interno, insubstituível, e que se confunde com a própria natureza da pessoa. ${ }^{23}$

É possível extrair desse raciocínio que a dignidade da pessoa humana é, acima de tudo, um valor fundamental inerente aos seres humanos, posteriormente englobado pelo Direito, transformado em princípio constitucional expressamente positivado ou passível de ser retirado do ordenamento legal. $\mathrm{O}$ embasamento legal desse conceito fortalece a justificação dos direitos fundamentais, que possuem razão moral e legal de ser. ${ }^{24}$

É a partir disso que se nota que a dignidade da pessoa humana não é uma criação do ordenamento jurídico, mas um valor prévio, indissociável da existência humana. Ou seja, a pessoa humana é tutelada por um corpo legal que esta mesma como ser racional que é instituiu, e deve, para poder estar incluída verdadeiramente, ser diretamente vinculada à sua dignidade fundamental. ${ }^{25}$ Sendo assim, a Constituição apenas a tomou como um valor supremo na norma jurídica ao declará-la como um dos fundamentos da República Federativa do Brasil.

\section{$4 \quad$ PRISÕES COMO INSTITUIÇÕES TOTAIS}

Nos tempos atuais, no entanto, a pena privativa de liberdade não tem cumprido com suas principais funções de ressocialização e de atenuação da possibilidade de reincidência criminal. Para explicar tal

\footnotetext{
${ }^{23}$ SILVA, José Afonso da. A dignidade da pessoa humana como valor supremo da democracia. In: Revista de Direito Administrativo, v. 212, Rio de Janeiro, 1998. p. 91. Disponível em: http://bibliotecadigital.fgv.br/ojs/index.php/rda/article/view/47169 Acesso em: 02 de fevereiro de 2019.

${ }^{24}$ BARroso, Luís Roberto. A Dignidade da Pessoa Humana no Direito Constitucional Contemporâneo: Natureza Jurídica, Conteúdos Mínimos e Critérios de Aplicação. Versão provisória para debate público. Mimeografado, 2010. p. 11.

${ }^{25}$ SILVA, José Afonso da. A dignidade da pessoa humana como valor supremo da democracia. In: Revista de Direito Administrativo, v. 212, Rio de Janeiro, 1998. p. 91. Disponível em: http://bibliotecadigital.fgv.br/ojs/index.php/rda/article/view/47169 Acesso em: 02 de fevereiro de 2019.
} 
fenômeno, faz-se necessário uma breve explanação acerca desta problemática e de suas causas, no sistema prisional tradicional. ${ }^{26}$

A prisão entra como uma escola que além de destituir de subjetividades próprias do apenado, introjeta nestes estes estereótipos socialmente construídos. Nesse contexto, a sociedade, além de produtora de estereótipos, ainda não educa e socializa verdadeiramente, sobretudo seus estratos mais frágeis. Assim, antes da problemática da ressocialização e reeducação, a questãoé de educação e socialização prévia. Não se pode pensar em reeducação para uma parcela da sociedade que inicialmente não foi educada. ${ }^{27}$

Este processo de "educação para o crime" de dentro das prisões toma força na medida em que o cárcere promove um profundo ritual de degradação, que destitui do encarcerado vários de seus símbolos externos, que faziam parte de sua identidade (exemplo disso são os objetos pessoais, as roupas e até mesmo nome), e oferecem outros, de forma padronizante. Ou seja, ocorre um profundo processo de desaculturação do condenado para a vida em liberdade, e de aculturação para a internalização dos estereótipos próprios da vida do cárcere e da subcultura prisional. ${ }^{28} \mathrm{Com}$ os rituais de degradação tão constantes na rotina carcerária, a prisão passa a favorecer ainda mais a organização deste ambiente de escola para o crime, com presos solidários entre si. $^{29}$

Além da educação para o crime, pode-se considerar que há um profundo processo de "educação para ser bom preso". Este se perpetua na aceitação das regras formais da instituição, assim como as informais postas pela equipe carcerária em troca de privilégios aos comandantes dos detidos. Nesse caso, após o longo processo de dessubjetivação, há a interiorização de modelos de comportamentos externos, propagados pela lógica carcerária. $^{30}$

As prisões tradicionais baseiam seu funcionamento essencialmente na prática disciplinar. Muitos processos disciplinares existem já há muito tempo, e em diferentes contextos, como conventos,

\footnotetext{
${ }^{26}$ TRINDADE, Lourival Almeida. A Ressocialização...uma (dis)função da pena de prisão. Porto Alegre: SAFE, 2003. p. 13.

${ }^{27}$ TRINDADE, Lourival Almeida. A Ressocialização...uma (dis)função da pena de prisão. Porto Alegre: SAFE, 2003. p. 20 e p.50.

28 AZEVÊDO, Jackson Chaves de. Reforma e "contra"-reforma penal (1984-1996): uma ilusão...que sobrevive. Florianópolis, 1997. p.36.

${ }^{29}$ FOUCAULT, Michel. Vigiar e Punir. 20 ed. Petrópolis: Vozes, 1999. p. 222

${ }^{30}$ BARATTA, Alessandro. Criminologia Crítica e Crítica do Direito Penal: introdução à sociologia do direito penal. 3 ed. Rio de Janeiro: Editora Revan, 2002. p.185.
} 
exércitos, oficinas, manicômios, etc. Ao passo que a disciplina religiosa traz consigo a compreensão e necessidade da realização de renúncias, as disciplinas ali empregadas rendem uma postura de corpo dócil, corpo este totalmente entregue à utilidade, assujeitado, e portando absolutamente responsivo à dominação constante, integral e não analítica. A mesma disciplina que pode aumentar os poderes do corpo, diminui em termos de autonomia em detrimento da obediência. Esta, por sua vez, que tem como objetivo último um domínio sobre o corpo e sobre a vida. Assim como o poder econômico na exploração do trabalho divide força de trabalho de produto final, o modelo coercitivo disciplinar formula uma aptidão utilitária docilizada com aumento da dominação. ${ }^{31}$

É nesse ponto que se entende a prisão tradicional como um fracasso da justiça penal. Estas não reduzem os índices de criminalidade, podendo, na verdade, aumentá-los, multiplicá-los, sendo que a quantidade de crimes e criminosos se mantém o mesmo ou aumenta, reflexo desse sistema de produção de delinquência. ${ }^{32}$

A partir deste jogo de submissão ao poder que o prisioneiro experencia, muitas vezes cria um verdadeiro sentimento de injustiça, que somente fortalece seu processo de "educação para o crime". Na experiência de sofrimentos para além dos previstos pela pena privativa de liberdade, passa a ver o poder judicial (e seus representantes) como injustos: para ele, não é mais culpado, mas injustiçado. ${ }^{33}$

Além deste tratamento degradante dado aos aprisionados, devese levar em conta as condições impostas na vida egressa. Elas reforçam ainda mais a possibilidade de reincidência, a partir não só do estigma de "ex-detento" (alcunha recebida, também reflexo da dessubjetivação), como um verdadeiro passaporte que indica sua condição anterior. Soma-se ainda a vigilância constante da polícia, tornando-se um grupo visado pelas

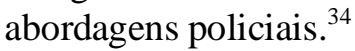

Essa análise dialoga com a perspectiva de análise que coloca a prisão como um dos diferentes tipos de "instituições totais". Estas são representadas por locais de residência e trabalho de permanência considerável, com muitos indivíduos passando por uma situação padronizada, totalmente administrada, reclusa e separada da sociedade. Nesta, o interno reformula totalmente sua forma de ser, após o

\footnotetext{
${ }^{31}$ FOUCAULT, Michel. Vigiar e Punir. 20 ed. Petrópolis: Vozes, 1999, p. 118 e 119

${ }^{32}$ Ibidem, p. 221.

${ }^{33}$ Ibidem, p. 222.

${ }^{34}$ Ibidem, p. 223.
} 
aniquilamento de sua subjetividade, a partir da lógica de funcionamento destas instituições. A prisionização nestas instituições totais, além do processo de aniquilação da subjetividade promovida pela perda de elementos individuais, soma-se com uma rotina constantemente coletiva e sem qualquer possibilidade de vida sem exposição. ${ }^{35}$

Além dos processos vexatórios e de direta mortificação do eu, nota-se que nas instituições totais os aprisionados passam por formas indiretas deste mesmo processo. Como exemplo disto, é a perda parcial ou total da autonomia e da gerência da própria vida. Nestas instituições, as menores atividades do aprisionado podem estar sujeitas às regras internas ou ao arbítrio dos funcionários e da gerência. A vida de do internado é frequentemente penetrada e violada, em decorrência das sanções impostas que demarcam a posição inferiorizada que o aprisionado é submetido. É, de forma geral, uma violência sobre a autonomia das atividades. ${ }^{36}$

É notável também, que no processo de prisionização ocorre uma distinção entre "bons" e "maus", sendo os "maus" aqueles que foram condenados. Esta é uma das funções da pena: criar e reforçar uma identidade enxergada de forma negativa pela sociedade, o que só contribui para a exclusão social e cria uma verdadeira contradição no que tange a questão da ressocialização. Fala-se em ressocializar e cria-se um sistema de segregação. ${ }^{37}$ Esta perspectiva se aproxima da visão de Foucault, que entende que deveríamos substituir a ideia de que a prisão falha em reduzir crimes e ressocializar pela ideia de que ela tem, na realidade, obtido muito êxito em produzir a delinquência. É possível dizer, assim, que o sistema ao se deparar com o "fracasso", reforma, não muda e produz o mesmo. Nesse sentido, pode-se afirmar que o sistema fabrica o produto que consome, justificando sua existência. ${ }^{38}$ Este modelo de execução penal, portanto, baseado nos centros de detenção tradicionais, produz efeitos inversos ao objetivo de sua existência, quais sejam a reeducação e a reinserção social, estabilizando a inserção do condenado na população criminosa. ${ }^{39} 40$

É sobretudo um mal quando as penas que incidem sobre o acusado são de maior peso que o crime tem para a sociedade e a vantagem

\footnotetext{
${ }^{35}$ GOFFMAN, Erving. Manicômios, prisões e conventos. 9 ed. São Paulo: Perspectiva, 2015. p. 11

${ }^{36}$ Ibidem, p .42.

${ }^{37}$ TRINDADE, Lourival Almeida. A Ressocialização...uma (dis)função da pena de prisão. Porto Alegre: SAFE, 2003. p. 35.

${ }^{38}$ Ibidem, p. 19.

${ }^{39}$ BARATTA, Alessandro. Criminologia Crítica e Crítica do Direito Penal: introdução à sociologia do direito penal. 3 ed. Rio de Janeiro: Editora Revan, 2002. p. 183.

${ }^{40}$ FOUCAULT, Michel. Vigiar e Punir. 20 ed. Petrópolis: Vozes, 1999.
} 
por ele obtida. Neste sentido, a prisão tradicional é uma "horrível mansão do desespero e da fome", sendo necessário a entrada da compaixão e da humanidade em tais recintos e nas pessoas dos executores das penas. ${ }^{41} \mathrm{~A}$ finalidade da pena não é "atormentar e afligir" o condenadoou ainda desfazer o delito anteriormente cometido. As penas muito rígidas e que trazem sofrimento são, assim, inúteis. Quanto mais rígidas são as penas infligidas ao condenado, maior será sua busca em tentar evitá-las, somando crimes para que os primeiros sejam ocultados. ${ }^{42}$

\section{MÉTODO APAC}

A APAC surge de maneira a cumprir com maior proximidade ambas as finalidades da pena - punitiva e ressocializadora - concomitante ainda com a humanização do ambiente carcerário. ${ }^{43}$ Trata-se de importante passo em direção ao ideal na execução penal brasileira. ${ }^{44}$

O método APAC propõe um modelo de execução penal em que a valorização da pessoa humana através da manutenção e fortalecimento da dignidade se constitui como uma força motriz para o desenvolvimento integral dos sujeitos: físico, profissional, intelectual moral e espiritual. As APACs, com a legitimidade conferida por lei, cujo estatuto é amparado pela Constituição Federal, pelo Código Civil e pela Lei de Execução Penal $^{45}$, além do espaço fornecido pelo Estado, promovem o referido trabalho assistencial e ainda propiciam um ambiente mais pacífico de maneira que o resultado há de conferir ao detento o poder de escolha acerca de seu futuro. ${ }^{46}$ Como forma de promover todo esse processo, a metodologia se pauta em 12 pilares de sustentação, quais sejam: 1) Participação da comunidade;2) Recuperando ajudando recuperando;3) Trabalho;4) Religião;5) Assistência jurídica;6) Assistência à saúde;7)

\footnotetext{
${ }^{41}$ BECCARIA, Cesare. Dos Delitos e das Penas. Rio de Janeiro, Editora Nova Fronteira, 2016, p. 30.

${ }^{42}$ Ibidem, p. 54 , p. 55 e p. 57.

${ }^{43}$ GENIPAPEIRO, Fernando Padilha. A humanização da pena e a ressocialização do condenado: um estudo sobre a APAC. Trabalho de Conclusão de Curso (Direito Penal) - Faculdade de Direto da Universidade de Itaúna. Itaúna, 2017. p. 12.

${ }^{44}$ SILVA, Jane Ribeiro (Org.). A execução penal à luz do método APAC. Belo Horizonte: Tribunal de Justiça de Minas Gerais, 2012. p. 54

${ }^{45}$ GENIPAPEIRO, Fernando Padilha. A humanização da pena e a ressocialização do condenado: um estudo sobre a APAC. Trabalho de Conclusão de Curso (Direito Penal) - Faculdade de Direto da Universidade de Itaúna. Itaúna, 2017. p. 11.

${ }^{46}$ SILVA, Jane Ribeiro (Org.). A execução penal à luz do método APAC. Belo Horizonte: Tribunal de Justiça de Minas Gerais, 2012. p. 42.
} 
Valorização humana;8) A família;9) O voluntário e sua formação;10) Centro de reintegração social;11)Mérito;12) Jornada de libertação com Cristo.

Em relação à participação da comunidade, o sistema APAC se baseiana participação ativa da população no dia a dia do estabelecimento prisional dos modos mais variados (com a apresentação de exemplos de vida, lições e discussões bem como doações de roupas e materiais de uso pessoal) despertará no preso não só a sensação de inclusão, mas também a esperança de que existem outros caminhos que não o do crime. Aqueles que foram vítimas de crimes devem também atuar conjuntamente com a APAC sempre na busca do saneamento da delinquência. ${ }^{47} 4849$

A comunidade ainda se integra na rotina das APACs, seja como voluntária ou visitante, com a busca pelos internos em mostrar sua realidade de redenção real de erros cometidos no passado através de atividades e valores desenvolvidos ao longo do cumprimento da pena. Esta relação auxilia a comunidade a compreender a importância e relevância social da APAC, se tornando em sequência, um potencial difusor do método. ${ }^{50} \mathrm{O}$ pilar da participação da comunidade está em consonância com a Lei de Execução Penal, em seu artigo $4^{\circ}$, que prevê a cooperação da comunidade com o Estado na execução penal. ${ }^{51}$

Há também a inclusão por parte dos recuperandos que, ao chegarem a uma APAC, são acolhidos pelos demais ali presentes que podem compartilhar de histórias de vida semelhantes. Os detentos dividem responsabilidades e aprendem não só a fazer parte de algo como também verdadeiros limites para uma harmônica convivência em sociedade. Este

\footnotetext{
${ }^{47}$ SILVA, Jane Ribeiro (Org.). A execução penal à luz do método APAC. Belo Horizonte: Tribunal de Justiça de Minas Gerais, 2012. p.43, 44 e 57.

${ }^{48}$ GENIPAPEIRO, Fernando Padilha. A humanização da pena e a ressocialização do condenado: um estudo sobre a APAC. Trabalho de Conclusão de Curso (Direito Penal) - Faculdade de Direto da Universidade de Itaúna. Itaúna, 2017. p. 14.

${ }^{49}$ FUZATTO, Antônio Carlos de Jesus. Socialização no sistema prisional convencional e alternativo em Minas Gerais: estudo com encarcerados. Dissertação (Mestrado em Educação e Sociedade) Universidade Presidente Antônio Carlos (UNIPAC). Barbacena, 2008. p. 48.

${ }^{50}$ GENIPAPEIRO, Fernando Padilha. A humanização da pena e a ressocialização do condenado: um estudo sobre a APAC. Trabalho de Conclusão de Curso (Direito Penal) - Faculdade de Direto da Universidade de Itaúna. Itaúna, 2017. p. 15.

51 BRASIL. Lei $\mathrm{n}^{\circ} 7.2010$ de 11 de julho de 1984. Disponível em: http://www.planalto.gov.br/ccivil_03/leis/17210.htm. Acesso em: 01 de julho de 2019
} 
elemento (recuperando ajudando recuperando) entende que a cooperação destes é fator propulsor de resultados positivos. ${ }^{52} 5354$

O trabalhodesenvolve na pessoa interesses por alguma atividade com a qual possa futuramente exercer, respeitando o princípio da dignidade humana e ainda facilitando sua reinserção social. A atividade laboral, obrigatória em todos os regimes, não é realizada de maneira forçada respeitando-se o livre arbítrio e comprometimento com a jornada de ressocialização. A prática de um ofício evita a ociosidade presente nos presídios atuais além de proporcionar elevação da autoestima do pre so. ${ }^{55}$

Nos diferentes regimes de pena, fechado, semi-aberto e aberto, o trabalho é realizado de forma distinta, de maneira a cumprir os objetivos do método. No regime fechado o trabalho efetuado de forma artesanal e tem função terapêutica. No semi-aberto, a APAC se volta para a profissionalização do recuperando, para que este desenvolva habilidades que possam ser utilizadas na vida egressa no mundo do trabalho. Dessa forma, há participação de empresas parceiras (como o SENAI) às quais desenvolvem projetos na APAC com objetivo de capacitação profissional. Por fim, no regime aberto, os recuperando já se encontram trabalhando no ambiente externo e a APAC se volta para a reinserção social. ${ }^{56} 57$

A religião está relacionada à espiritualidade do indivíduo, sendo uma forma de cuidar do espírito e realizar uma reflexão acerca de valores morais. As APACs se pautam na experiência divina, sem, no entanto, impor qualquer credo. Destaca-se que nenhuma assistência isoladamente terá impacto ressocializador desejado, ou seja, todos os pilares devem estar presentes. A assistência religiosa é prevista pelo artigo 11 e especificado

\footnotetext{
${ }^{52}$ SILVA, Jane Ribeiro (Org.). A execução penal à luz do método APAC. Belo Horizonte: Tribunal de Justiça de Minas Gerais, 2012. p. 44.

${ }^{53}$ GENIPAPEIRO, Fernando Padilha. A humanização da pena e a ressocialização do condenado: um estudo sobre a APAC. Trabalho de Conclusão de Curso (Direito Penal) - Faculdade de Direto da Universidade de Itaúna. Itaúna, 2017. p. 16.

${ }^{54}$ FUZATTO, Antônio Carlos de Jesus. Socialização no sistema prisional convencional e alternativo em Minas Gerais: estudo com encarcerados. Dissertação (Mestrado em Educação e Sociedade) Universidade Presidente Antônio Carlos (UNIPAC). Barbacena, 2008. p. 48 e 49.

${ }^{55}$ Ibidem, p. 52.

${ }^{56}$ GENIPAPEIRO, Fernando Padilha. A humanização da pena e a ressocialização do condenado: um estudo sobre a APAC. Trabalho de Conclusão de Curso (Direito Penal) - Faculdade de Direto da Universidade de Itaúna. Itaúna, 2017. p. 16 e 17.

${ }^{57}$ FUZATTO, Antônio Carlos de Jesus. Socialização no sistema prisional convencional e alternativo em Minas Gerais: estudo com encarcerados. Dissertação (Mestrado em Educação e Sociedade) Universidade Presidente Antônio Carlos (UNIPAC). Barbacena, 2008. p. 52.
} 
pelo artigo 24 da LEP, garantindo liberdade de culto e garantindo a possibilidade de participação em instrução religiosa.

A assistência jurídica possui elevada importância uma vez que trará tranquilidade ao preso, ao compreender sua situação legal, e consequentemente ao ambiente prisional. Os Centros de Reintegração Social (local onde as APACs estão instaladas) contam com setor jurídico específico que presta assistência aos recuperandos. Tudo é feito de maneira transparente para que a angústia existente sobre sua situação jurídica seja extinta e o preso possa manter seu foco na própria recuperação. ${ }^{61} 6263$

Ante à dificuldade da assistência pública em alcançar os ambientes carcerários unido ao verdadeiro descaso de boa parte da população, os internos das APACs contam com assistência à saúde. As queixas dos internos em relação a dores, além de adoecimento mental gerado pela privação de liberdade são constantes. As APACs contam com consultórios médicos, odontológicos e psicológicos que periodicamente atendem a população carcerária e consequentemente ainda contribuem para um aumento e resgate da autoestima -interna e externa - do recuperando. ${ }^{64}$ A presença do voluntariado nesse setor também fortalece o preso pois traz o sentimento de valorização e de ser enxergado pela sociedade (digno de recuperação). ${ }^{65} 66$

Este pilar da metodologia apaqueana é fundamentado pela Constituição Federal em seu artigo 196: “Art. 196. A saúde é direito de

\footnotetext{
${ }^{58}$ SILVA, Jane Ribeiro (Org.). A execução penal à luz do método APAC. Belo Horizonte: Tribunal de Justiça de Minas Gerais, 2012. p. 45 e 46.

${ }^{59}$ GENIPAPEIRO, Fernando Padilha. A humanização da pena e a ressocialização do condenado: um estudo sobre a APAC. Trabalho de Conclusão de Curso (Direito Penal) - Faculdade de Direto da Universidade de Itaúna. Itaúna, 2017. p. 17

60 BRASIL. Lei $\mathrm{n}^{\circ} 7.2010$ de 11 de julho de 1984 . Disponível em: http://www.planalto.gov.br/ccivil_03/leis/17210.htm. Acesso em: 01 de julho de 2019

${ }^{61}$ SILVA, Jane Ribeiro (Org.). A execução penal à luz do método APAC. Belo Horizonte: Tribunal de Justiça de Minas Gerais, 2012. p. 46 e 47.

${ }^{62}$ GENIPAPEIRO, Fernando Padilha. A humanização da pena e a ressocialização do condenado: um estudo sobre a APAC. Trabalho de Conclusão de Curso (Direito Penal) - Faculdade de Direto da Universidade de Itaúna. Itaúna, 2017. p. 18.

${ }^{63}$ FUZATTO, Antônio Carlos de Jesus. Socialização no sistema prisional convencional e alternativo em Minas Gerais: estudo com encarcerados. Dissertação (Mestrado em Educação e Sociedade) Universidade Presidente Antônio Carlos (UNIPAC). Barbacena, 2008. p. 51 e 52.

${ }^{64}$ Ibidem, p. 52.

${ }^{65}$ SILVA, Jane Ribeiro (Org.). A execução penal à luz do método APAC. Belo Horizonte: Tribunal de Justiça de Minas Gerais, 2012. P. 47 e 48

${ }^{66}$ GENIPAPEIRO, Fernando Padilha. A humanização da pena e a ressocialização do condenado: um estudo sobre a APAC. Trabalho de Conclusão de Curso (Direito Penal) - Faculdade de Direto da Universidade de Itaúna. Itaúna, 2017. p. 19.
} 
todos e dever do Estado, garantido mediante políticas sociais e econômicas que visem à redução do risco de doença e de outros agravos e ao aceso universal e igualitário às ações e serviços para sua promoção, proteção e recuperação." ${ }^{, 67}$

Também é previsto pelo artigo 14, caput, da LEP, "A assistência à saúde do preso e do internado, de caráter preventivo e curativo, compreenderá atendimento médico, farmacêutico e odontológico." 68

A valorização humana proporciona ao apenado, além de esperança, um verdadeiro sentimento de vida nova. Juntamente com a assistência educacional elas fornecem novas oportunidades, não apenas de trabalho, mas de vida. Tal valorização é exemplificada pelo tratamento dado ao recuperando, ao ser chamado pelo próprio nome, ao ser ouvido e ser compreendida sua vida pregressa, bem como seus desejos, sonhos, expectativas, entre outras formas. ${ }^{69} 7071$

A convivência com a família, através de visitas regulares, também proporciona ao recuperando o amor, a esperança e valorização que necessita para sua ressocialização. Porém, deve ser realizada em ambiente de tranquilidade e de modo respeitoso, uma vez que a família do preso também sofre a pena e a estigmatização. O convívio familiar é uma das maneiras de assistência social e, ainda retira do apenado a sensação de que foi abandonado pelos seus familiares. Nas APACs os familiares estão sempre presentes e participam ativamente do curso de recuperação do familiar preso, para isso, recebem uma preparação através de cursos que os sensibilizam para a acolhida do recuperando. O núcleo familiar deve ainda conhecer, zelar e disseminar a metodologia apaqueana. ${ }^{72} 73$

\footnotetext{
${ }^{67}$ BRASIL, Constituição (1988). Constituição da República Federativa do Brasil. Sã o Paulo: Rideel, 2016

68 BRASIL. Lei $\mathrm{n}^{\circ} 7.2010$ de 11 de julho de 1984 . Disponível em:http://www.planalto.gov.br/ccivil_03/leis/17210.htm. Acesso em: 01 de julho de 2019

${ }^{69}$ SILVA, Jane Ribeiro (Org.). A execução penal à luz do método APAC. Belo Horizonte: Tribunal de Justiça de Minas Gerais, 2012. p. 48 e 58.

${ }^{70}$ GENIPAPEIRO, Fernando Padilha. A humanização da pena e a ressocialização do condenado: um estudo sobre a APAC. Trabalho de Conclusão de Curso (Direito Penal) - Faculdade de Direto da Universidade de Itaúna. Itaúna, 2017. p. 23.

${ }^{71}$ FUZATTO, Antônio Carlos de Jesus. Socialização no sistema prisional convencional e alternativo em Minas Gerais: estudo com encarcerados. Dissertação (Mestrado em Educação e Sociedade) Universidade Presidente Antônio Carlos (UNIPAC). Barbacena, 2008. p. 47.

${ }^{72}$ SILVA, Jane Ribeiro (Org.). A execução penal à luz do método APAC. Belo Horizonte: Tribunal de Justiça de Minas Gerais, 2012. p. 49.

${ }^{73}$ GENIPAPEIRO, Fernando Padilha. A humanização da pena e a ressocialização do condenado: um estudo sobre a APAC. Trabalho de Conclusão de Curso (Direito Penal) - Faculdade de Direto da Universidade de Itaúna. Itaúna, 2017. p. 19 e 20.
} 
Tem-se ainda a importância da formação qualificada dos voluntários responsáveis por participar ativamente da prestação de todas as demais assistências. Dessa forma, tais voluntários são submetidos a cursos preparatórios para que possam transmitir valores éticos e morais condizentes e de maneira clara, evitando o improviso na execução penal, contribuindo para com a autoestima e reestruturação do preso. ${ }^{74} 757677$

A presença de departamentos especializados em direito, saúde, bem como de um setor administrativo responsável por gerir os Centros de Reintegração Social (CRS) e proporcionar condições higiênicas e sanitárias mínimas para o cumprimento da pena é meio para a prestação da assistência material citada no dispositivo legal. Dessa forma o art.41 da LEP preconiza os direitos do encarcerado, quais sejam: alimentação, vestuário, trabalho remunerado, saúde dentre outros também assegurados pela Constituição Federal de 1988. Destes, a assistência material engloba, segundo o constante no artigo 12 do referido dispositivo legal, o provimento de alimentação, instalações higiênicas e vestuário. Em continuidade, o art. 13 dispõe sobre a existência de serviços e instalações que atendam as necessidades do detento, bem como disponha de ambientes destinados à venda de produtos e objetos permitidos e não fornecidos pela Administração. Nas APACs a responsabilidade pela higiene pessoal e do ambiente cabe aos recuperandos de forma a instituir uma disciplina e rotina, bem como despertar a consciência e o comprometimento do interno, sendo o objetivo final a busca por um ambiente harmônico para os mesmos. $^{78}$

Os CRS englobam ainda a existência de ambientes dignos celas, cozinha, espaços para receber a família - a devida separação de regimes sendo composto por três pavilhões (fechado, aberto e semiaberto) destinados ao cumprimento da pena de acordo com a LEP e com respeito à capacidade de lotação do ambiente. Em suma, um ambiente carcerário

\footnotetext{
${ }^{74}$ SILVA, Jane Ribeiro (Org.). A execução penal à luz do método APAC. Belo Horizonte: Tribunal de Justiça de Minas Gerais, 2012. p. 50.

${ }^{75}$ GENIPAPEIRO, Fernando Padilha. A humanização da pena e a ressocialização do condenado: um estudo sobre a APAC. Trabalho de Conclusão de Curso (Direito Penal) - Faculdade de Direto da Universidade de Itaúna. Itaúna, 2017. p. 20

${ }^{76}$ FUZATTO, Antônio Carlos de Jesus. Socialização no sistema prisional convencional e alternativo em Minas Gerais: estudo com encarcerados. Dissertação (Mestrado em Educação e Sociedade) Universidade Presidente Antônio Carlos (UNIPAC). Barbacena, 2008. p. 50 e 51.

${ }^{77} \mathrm{O}$ modelo prevê gratuidade, sendo a remuneração restrita aos funcionários do setor administrativo.

${ }^{78}$ SILVA, Jane Ribeiro (Org.). A execução penal à luz do método APAC. Belo Horizonte: Tribunal de Justiça de Minas Gerais, 2012. p. 61 e 62.
} 
com condições mínimas de dignidade proporcionará, consequentemente, melhores condições de reinserção para o interno. ${ }^{79} 80$

$\mathrm{Na}$ metodologia APAC ainda estão presentes os Comitês Técnicos de Classificação (CTC) os quais são responsáveis pela rigorosa avaliação e apuração do mérito do recuperando. O interno é avaliado desde o primeiro dia na instituição, inclusive pelos próprios colegas que formam os Conselhos de Sinceridade e Solidariedade (CSSs). Estes analisam a jornada, o ímpeto de recuperação e sua receptividade às modalidades assistenciais recebidas, bem como inicialmente designam seu trabalho. ${ }^{8182}$ $\mathrm{O}$ mérito visa estimular os recuperandos a adquirir papéis em todo o sistema, participando ativamente da rotina institucional. ${ }^{83}$ Os CTCs são formados pelo pessoal que participa da rotina dos presos, ou seja, são voluntários, funcionários e dirigentes. Têm, essas pessoas, a função de acompanhar os presos dentro do sistema, proferindo opiniões sobre a concessão de benefícios. O mérito fornece meio de despertar o recuperando para o interesse na metodologia e para as mudanças de vida. ${ }^{84} 85$

Por fim, a Jornada de Libertação com Cristo é realizada anualmente em um encontro com duração de quatro dias. É uma maneira de assistência religiosa que desenvolve intensa reflexão espiritual, além possibilitar autoconhecimento. O preso encara suas qualidades e defeitos frente valores éticos e morais proporcionados pelos ensinamentos

\footnotetext{
${ }^{79}$ SILVA, Jane Ribeiro (Org.). A execução penal à luz do método APAC. Belo Horizonte: Tribunal de Justiça de Minas Gerais, 2012. p. 50, 51 e 59.

${ }^{80}$ GENIPAPEIRO, Fernando Padilha. A humanização da pena e a ressocialização do condenado: um estudo sobre a APAC. Trabalho de Conclusão de Curso (Direito Penal) - Faculdade de Direto da Universidade de Itaúna. Itaúna, 2017. p. 21.

${ }^{81}$ Ibidem, p. 16.

${ }^{82}$ FUZATTO, Antônio Carlos de Jesus. Socialização no sistema prisional convencional e alternativo em Minas Gerais: estudo com encarcerados. Dissertação (Mestrado em Educação e Sociedade) Universidade Presidente Antônio Carlos (UNIPAC). Barbacena, 2008. p. 49.

${ }^{83}$ Ibidem, p. 47 e 48.

${ }^{84}$ SILVA, Jane Ribeiro (Org.). A execução penal à luz do método APAC. Belo Horizonte: Tribunal de Justiça de Minas Gerais, 2012. p. 51.

${ }^{85}$ GENIPAPEIRO, Fernando Padilha. A humanização da pena e a ressocialização do condenado: um estudo sobre a APAC. Trabalho de Conclusão de Curso (Direito Penal) - Faculdade de Direto da Universidade de Itaúna. Itaúna, 2017. p. 22.
} 
religiosos. Ao término, ganha forças para seguir em sua ressocialização orientando pelo livre arbítrio. ${ }^{868788}$

A APAC trabalha através de estágios, de maneira a restabelecer e até mesmo modificar valores no íntimo do condenado. Na etapa inicial pretende-se que o recuperando desenvolva senso de responsabilidade, abordando as causas do cometimento do crime, sendo ainda feito o primeiro contato familiar. No segundo estágio, o objetivo é inserir os recuperandos na sistemática apaqueana, sendo assim designados aos mesmos trabalhos burocráticos, conferindo-lhes responsabilidades.

Notam-se grandes diferenças entre o sistema prisional tradicional eas APACs, com resultados muito distintos.A diferença não recai apenas quanto ao nível de reincidência, por exemplo(15\% das APACs em contraste com a reincidência de $70 \%$ apresentada pelo sistema prisional comum).$^{89}$ Esta só se torna possível por uma reestruturação do modo como a execução penal tem sido realizada no Brasil, hegemonicamente distante do disposto na Lei de Execução Penal. Areferida Lei contém avanços significativos na forma como as penas devem ser estruturadas e cumpridas no país, de acordo com todo um aparato legal mundial anterior referente aos Direitos Humanos.

Desde o primeiro título até o último da presente Lei, ambos sistemasse diferenciam muito, sobretudo no tocante à rotina carcerária propriamente dita. É evidente que mesmo as instituições prisionais tradicionais devem seguir orientações da lei, de forma a garantir o mínimo de sua implementação. No entanto, em termos de garantias básicas, como espaço adequado para o cumprimento da pena, individualização da pena e

\footnotetext{
${ }^{86}$ SILVA, Jane Ribeiro (Org.). A execução penal à luz do método APAC. Belo Horizonte: Tribunal de Justiça de Minas Gerais, 2012. p. 52

${ }^{87}$ GENIPAPEIRO, Fernando Padilha. A humanização da pena e a ressocialização do condenado: um estudo sobre a APAC. Trabalho de Conclusão de Curso (Direito Penal) - Faculdade de Direto da Universidade de Itaúna. Itaúna, 2017. p. 23

${ }^{88}$ FUZATTO, Antônio Carlos de Jesus. Socialização no sistema prisional convencional e alternativo em Minas Gerais: estudo com encarcerados. Dissertação (Mestrado em Educação e Sociedade) Universidade Presidente Antônio Carlos (UNIPAC). Barbacena, 2008. p. 53.

${ }^{89}$ SILVA, Jane Ribeiro (Org.). A execução penal à luz do método APAC. Belo Horizonte: Tribunal de Justiça de Minas Gerais, 2012. p. 77.
} 
garantia da valorização humana, sua aplicação é muito incipiente, ao passo que são elementos base nas APACs.

A discussão acerca das instituições totais se mostra pertinente na medida em que os estabelecimentos prisionais hegemônicos no Brasil, embora não sigam mais o modelo de punições físicas ou penas objetivamente cruéis, mantém uma estrutura de assujeitamento e de criação de uma personalidade criminosa. Ao despojar o condenado de todos os seus elementos pessoais que o identificam em prol de uma uniformização, contribui para a perda da identidade e o fortalecimento de estruturas que apenas perpetuam o ciclo do crime. ${ }^{90}{ }^{91}$ As APACs, contrariamente, não se baseiam nessa forma de lidar com o recuperando, respeitando-o em sua essência e buscando seu desenvolvimento pessoal por diferentes meios, reduzindo as chances de que o condenado busque associações que o reencaminhem para a marginalização.

Os princípios norteadores do método APAC, como exposto, estão profundamente atrelados com a busca da garantia do respeito à dignidade da pessoa humana. Esta entendida como um princípio constitucional intrínseco à todos os seres humanos sem qualquer distinção, isto é, se é homem é dotado de dignidade. Logo, não pode ser negado aos condenados unicamente por terem infringido a lei, visto que não há qualquer fator excludente da dignidade ${ }^{92}$. Este princípio passou por uma longa discussão e está incluída na LEP, na Constituição Federal, bem como outros aparatos legais, mas tem sido constantemente desrespeitado pela falência das penas de prisão como têm sido tradicionalmente realizadas no Brasil $^{94}$, contribuindo muito para o alto índice de reincidência e do fracasso ressocializador. É por esta razão que, ao partir incialmente deste simples princípio humanizador, as APACs avançam tanto no objetivo ressocializador das penas a partir da "harmônica integração social do condenado e do internado", através da colaboração entre voluntários e

\footnotetext{
${ }^{90}$ GOFFMAN, Erving. Manicômios, prisões e conventos. 9.ed. São Paulo: Perspectiva, 2015

${ }^{91}$ FOUCAULT, Michel. Vigiar e Punir. 20 ed. Petrópolis: Vozes, 1999

${ }^{92}$ SILVA, José Afonso da. A dignidade da pessoa humana como valor supremo da democracia. In: Revista de Direito Administrativo, v. 212, Rio de Janeiro, 1998.

93 BARRoso, Luís Roberto. A Dignidade da Pessoa Humana no Direito Constitucional Contemporâneo: Natureza Jurídica, Conteúdos Mínimos e Critérios de Aplicação. Versão provisória para debate público. Mimeografado, 2010

${ }^{94}$ BITENCOURT, Cezar Roberto. Falência da Pena de Prisão: causas e alternativas. 4 ed. São Paulo: Saraiva, 2011.
} 
comunidade, uso do exercício laboral, assistência ao condenado, reflexão moral e uma verdadeira valorização humana. ${ }^{95} 96$

Nota-se que o mérito das APACs em ser uma alternativa ao sistema prisional no Brasil (e também no mundo) é por apenas seguir os objetivos e disposições da Lei de Execução Penal, e isso se dá por uma série de fatores que contribuem para este fim. ${ }^{97} \mathrm{~A}$ união de princípios norteadores pautados da humanização da pena torna seus resultados mais eficazes e duradouros, podendo servir de modelo para repensar como as penas podem ser executadas em outros estabelecimentos penitenciários para que a crise deste sistema possa ser atenuada. A presente pesquisa se foca em aspectos gerais da metodologia apaqueana, não esgotando o tema. Entende-se que podem ser explorados ainda alguns elementos específicos da metodologia de forma mais refinada em pesquisas futuras para uma compreensão ainda maior sobre esta e sobre possíveis caminhos na execução penal.

\section{REFERÊNCIAS BIBLIOGRÁFICAS}

AZEVÊDO, Jackson Chaves de. Reforma e "contra"-reforma penal (1984-1996): uma ilusão...que sobrevive. Florianópolis, 1997.

BARATTA, Alessandro. Criminologia Crítica e Crítica do Direito Penal: introdução à sociologia do direito penal. 3 ed. Rio de Janeiro: Editora Revan, 2002.

BARROSO, Luís Roberto. A Dignidade da Pessoa Humana no Direito Constitucional Contemporâneo: Natureza Jurídica, Conteúdos Mínimos e Critérios de Aplicação. Versão provisória para debate público. Mimeografado, 2010.

BECCARIA, Cesare. Dos Delitos e das Penas. Rio de Janeiro, Editora Nova Fronteira, 2016.

BITENCOURT, Cezar Roberto. Falência da Pena de Prisão: causas e alternativas. 4 ed. São Paulo: Saraiva, 2011.

\footnotetext{
95 BRASIL. Lei $\mathrm{n}^{\text {o }} 7.2010$ de 11 de julho de 1984 . Disponível em: http://www.planalto.gov.br/ccivil_03/leis/17210.htm. Acesso em: 01 de julho de 2019.

${ }^{96}$ SILVA, Jane Ribeiro (Org.). A execução penal à luz do método APAC. Belo Horizonte: Tribunal de Justiça de Minas Gerais, 2012.

${ }^{97}$ GENIPAPEIRO, Fernando Padilha. A humanização da pena e a ressocialização do condenado: um estudo sobre a APAC. Trabalho de Conclusão de Curso (Direito Penal) - Faculdade de Direto da Universidade de Itaúna. Itaúna, 2017.p. 25.
} 
BRASIL, Constituição (1988). Constituição da República Federativa do Brasil. Sã o Paulo: Rideel, 2016.

BRASIL. Lei n ${ }^{\circ} 7.2010$ de 11 de julho de 1984. Disponível em: http://www.planalto.gov.br/ccivil_03/leis/17210.htm. Acesso em: 01 de julho de 2019.

BUTELLI, K.A.D. Projeto Novos Rumos na Execução Penal e o Método APAC - Uma abordagem jurídica e filosófica acerca da Lei 7210/84. 2011. 34 f. Monografia (Graduação Em Direito) - UniverCidade - Méier, Rio de Janeiro, 2011.

FOUCAULT, Michel. Vigiar e Punir. 20 ed. Petrópolis: Vozes, 1999.

FUZATTO, Antônio Carlos de Jesus. Socialização no sistema prisional convencional e alternativo em Minas Gerais: estudo com encarcerados. Dissertação (Mestrado em Educação e Sociedade) - Universidade Presidente Antônio Carlos (UNIPAC). Barbacena, 2008.

GENIPAPEIRO, Fernando Padilha. A humanização da pena e a ressocialização do condenado: um estudo sobre a APAC. Trabalho de Conclusão de Curso (Direito Penal) Faculdade de Direto da Universidade de Itaúna. Itaúna, 2017.

GOFFMAN, Erving. Manicômios, prisões e conventos. 9 ed. São Paulo: Perspectiva, 2015.

HENRIQUE, Derli Carolino da Silva. A Lei de Execução Penal e a Ressocialização do Apenado. Rede Doctum De Ensino, Vitória, dezembro de 2017

MARQUES JÚNIOR, Gessé. A lei de execuções penais e os limites da interpretação jurídica. Rev. Sociologia Política, Curitiba, v. 17, n. 33, p. 145-155, jun. 2009.

SILVA, Jane Ribeiro (Org.). A execução penal à luz do método APAC. Belo Horizonte: Tribunal de Justiça de Minas Gerais, 2012

SILVA, José Afonso da. A dignidade da pessoa humana como valor supremo da democracia. In: Revista de Direito Administrativo, v. 212, Rio de Janeiro, 1998. Disponível em: http://bibliotecadigital.fgv.br/ojs/index.php/rda/article/view/47169 Acesso em: 02 de fevereiro de 2019.

SILVA, José de Ribamar da. Prisão: ressocializar para não reincidir. Curitiba, 2003.

TRINDADE, Lourival Almeida. A Ressocialização...uma (dis)função da pena de prisão. Porto Alegre: SAFE, 2003. 